Mathematical Modelling and Analysis

Volume 5, 2000, PAGes 86-96

(C) 2000 Technika

\title{
THE ESTIMATES OF ACCURACY OF DIFFERENCE SCHEMES FOR THE NONLINEAR HEAT EQUATION WITH WEAK SOLUTION
}

\author{
B.S. JOVANOVIĆ ${ }^{1}$, P.P. MATUS ${ }^{2}$ and V.S. SHCHEHLIK ${ }^{3}$ \\ 1 University of Belgrade, Faculty of Mathematics, \\ Studentski trg 16, 11001, Belgrade, Yugoslavia, \\ 2,3 Institute of Mathematics, NAS of Belarus, \\ Surganov St. 11, 220072, Minsk, Belarus, \\ E-mail: ${ }^{1}$ bosko@matf.bg.ac.yu, ${ }^{2}$ matus@im.bas-net.by, \\ E-mail: ${ }^{3}$ schehlik@im.bas-net.by
}

Received August 30, 1999; revised October 29, 1999

\begin{abstract}
In this paper we study the convergence of explicit and implicit finite difference scheme for the first initial-boundary value problem for one dimensional quasilinear heat-conduction equation with "unbounded nonlinearity".
\end{abstract}

\section{INTRODUCTION}

In recent twenty years a great interest was devoted to the construction and analysis of finite difference schemes for approximation of boundary value problems with generalized solutions. In particular, finite difference schemes with convergence rate estimates consistent with the smoothness of data were of the major interest [7].

First results on the study of the convergence of discrete methods for problems with solution from Sobolev spaces were obtained in the theory of finite element methods. However, the methods of constructing difference schemes and obtaining consistent estimates differ from those applied in the finite element method.

For a wide variety of linear problems convergence rate estimates consistent 
with the smoothness of data are presented in $[7 ; 6 ; 9]$. However, as a rule, the most of actual problems are nonlinear, and the nature of the nonlinearities is diverse. For quasilinear elliptic equations with bounded nonlinearity, consistent convergence rate estimates have been obtained in $[1 ; 3]$. However, the requirements on coefficients of equations, such as positive definiteness, boundedness of partial derivatives over all values $u \in R^{n}$, narrows down the class of admissible input data of the problem.

The aim of this paper is to construct convergence rate estimates consistent with the smoothness of data for finite difference schemes approximating a nonlinear parabolic equation with generalized solution. Only minimal assumptions on the coefficients of equation are used.

\section{INITIAL-BOUNDARY VALUE PROBLEM}

In the rectangle $Q_{T}=\{(x, t): x \in \Omega=(0,1), 0<t<T\}$ for some $T>0$ we consider the initial-boundary value problem for quasilinear heat-conduction equation

$$
\begin{aligned}
& \frac{\partial u}{\partial t}=\frac{\partial}{\partial x}\left(k(u) \frac{\partial u}{\partial x}\right), \quad(x, t) \in Q_{T}, \\
& u(x, 0)=u_{0}(x), \quad x \in \Omega, \quad u(0, t)=u(1, t)=0, \quad 0<t<T .
\end{aligned}
$$

Let us introduce the Sobolev space $H^{s}(\Omega)$ of functions $u=u(x)$, defined on $\Omega$, and the anisotropic Sobolev space $H^{s, r}\left(Q_{T}\right)$ of functions $u=u(x, t)$, defined on $Q_{T}$. Let $H_{0}^{s}(\Omega)\left(H_{0}^{s, r}\left(Q_{T}\right)\right)$ denotes the closure of the set of infinitely smooth functions which are equal to 0 in the neighbourhood of $x=0$ and $x=1$ in the space $H^{s}(\Omega)\left(H^{s, r}\left(Q_{T}\right)\right)$ [2].

Definition 1.1. The element $u$ of the space $H^{2,1}\left(Q_{T}\right) \cap H_{0}^{1,0}\left(Q_{T}\right)$, satisfying (1.1) almost everywhere and equal $u_{0}(x)$ for $t=0$ is called generalized solution of the problem (1.1), (1.2).

Let us define the region of the exact solution $\mathcal{M}_{u}$ and its neighbourhood $\mathcal{D}_{u}$ :

$$
\begin{aligned}
& \mathcal{M}_{u}=\left\{u: u_{1} \leq u(x, t) \leq u_{2},(x, t) \in \bar{Q}_{T}\right\}, \\
& \mathcal{D}_{u}=\left\{\tilde{u}: u_{1}-\delta \leq \tilde{u}(x, t) \leq u_{2}+\delta, \quad(x, t) \in K \subseteq \bar{Q}_{T}\right\} .
\end{aligned}
$$

We assume, that there exists the unique solution $u(x, t)$ of the problem (1.1), (1.2) in $H^{2,1}\left(Q_{T}\right), u_{0} \in H^{1}(0,1)$, and $k \in C\left(\mathcal{D}_{u}\right), 0<k_{1} \leq k(v) \leq k_{2}$ for $v \in \mathcal{D}_{u}$. Note that similar problems are considered in [10;4].

Let us define the new function $\varphi(u)=\int_{0}^{u} k(w) d w$ and transform the equation (1.1) in the form

$$
\frac{\partial u}{\partial t}=\frac{\partial^{2} \varphi(u)}{\partial x^{2}}, \quad(x, t) \in Q_{T} .
$$




\section{EXPLICIT FINITE DIFFERENCE SCHEME}

Let us introduce uniform meshes

$$
\bar{\omega}_{\tau}=\left\{t_{j}=j \tau, j=\overline{0, j_{0}}, j_{0} \tau=T\right\}, \quad \bar{\omega}_{h}=\left\{x_{i}=i h, i=\overline{0, N}, N h=1\right\},
$$

and set $\omega_{\tau}=\bar{\omega}_{\tau} \cap[0, T), \omega_{h}=\bar{\omega}_{h} \cap(0,1)$ and $\omega_{h \tau}=\omega_{h} \times \omega_{\tau}$.

We define the discrete inner product $(v, w)_{h}=\sum_{x \in \omega_{h}} v(x) w(x) h$ and norms $\|v\|_{h}=(v, v)_{h}^{1 / 2},\|v\|_{C\left(\omega_{h}\right)}=\max _{x \in \bar{\omega}_{h}}|v(x)|,\|v\|_{h \tau}^{2}=\sum_{t \in \omega_{\tau}} \tau\|v(\cdot, t)\|_{h}^{2}$. We use the standard notation of the theory of difference schemes [5].

We define the Steklov averaging operators [7]

$$
\begin{gathered}
S_{t} f(x, t)=\frac{1}{\tau} \int_{t}^{t+\tau} f\left(x, t^{\prime}\right) d t^{\prime}, \quad S_{x} f(x, t)=\frac{1}{h} \int_{x-h / 2}^{x+h / 2} f\left(x^{\prime}, t\right) d x^{\prime}, \\
S_{x}^{2} f(x, t)=\frac{1}{h} \int_{x-h}^{x+h}\left(1-\frac{\left|x^{\prime}-x\right|}{h}\right) f\left(x^{\prime}, t\right) d x^{\prime},
\end{gathered}
$$

and we approximate the problem (1.5), (1.2) with the explicit finite difference scheme

$$
\begin{gathered}
y_{t}=(\varphi(y))_{\bar{x} x}, \quad(x, t) \in \omega_{h \tau}, \\
y(x, 0)=S_{x}^{2} u_{0}(x), \quad x \in \omega_{h}, \quad y(0, t)=y(1, t)=0, \quad t \in \bar{\omega}_{\tau} .
\end{gathered}
$$

Let us consider the convergence of finite difference scheme (2.1), (2.2) in the discrete norm $\|\cdot\|_{h \tau}$. Let us denote $\bar{u}=S_{x}^{2} u$ supposing that the solution $u(x, t)$ of the problem (1.5), (1.2) is oddly extended outside $Q_{T}$, i.e.

$$
\tilde{u}(x, t)= \begin{cases}-u(-x, t), & x \in(-1,0], \\ u(x, t), & x \in(0,1), \\ -u(2-x, t), & x \in[1,2) .\end{cases}
$$

It is easy to see [8], that

$$
\|\tilde{u}\|_{H^{2,1}\left(\tilde{Q}_{T}\right)}^{2}=3\|u\|_{H^{2,1}\left(Q_{T}\right)}^{2}, \quad \tilde{Q}_{T}=\{(x, t): x \in(-1,2), 0<t<T\} .
$$

Consequently, $\tilde{u} \in H^{2,1}\left(\tilde{Q}_{T}\right)$.

We define the error in the following manner $z=y-\bar{u}$. This error satisfies the finite difference scheme:

$$
z_{t}=(\varphi(\bar{u}+z)-\varphi(\bar{u}))_{\bar{x} x}-\eta_{\bar{x} x}, \quad(x, t) \in \omega_{h \tau}, \quad \eta=S_{t} \varphi(u)-\varphi(\bar{u})
$$




$$
z(x, 0)=0, \quad x \in \omega_{h}, \quad z(0, t)=z(1, t)=0, \quad t \in \bar{\omega}_{\tau} .
$$

Let us define the space $H$ of functions defined on the mesh $\bar{\omega}_{h}$ which vanish for $x=0$ and $x=1$. In the space $H$ with inner product $(\cdot, \cdot)_{h}$ and norm $\|\cdot\|_{h}$ we define the linear operator $A v=-v_{\bar{x} x}$.

It follows from $\varphi(0)=0, \varphi(u(0, t))=\varphi(u(1, t))=0$ and the definition of $\eta$ that $\eta(0, t)=\eta(1, t)=0$. Consequently, the problem (2.3), (2.4) can be represented in operator form

$$
z_{t}+A \kappa z=A \eta, \quad t \in \bar{\omega}_{\tau}, \quad z(0)=0,
$$

where $\varphi(\bar{u}+z)-\varphi(\bar{u})=\int_{\bar{u}}^{\bar{u}+z} k(w) d w=k(\bar{u}+\theta z) z=\kappa z, \theta \in(0,1)$.

Theorem 2.1. Suppose there exists the unique solution of the problem (1.1), (1.2) in $H^{2,1}\left(Q_{T}\right), k \in C\left(\mathcal{D}_{u}\right), 0<k_{1} \leq k(v) \leq k_{2}$ for $v \in \mathcal{D}_{u}$. Then, for sufficiently small $h<h_{0}, \tau<\tau_{0}$ and $\tau \leq \frac{k_{1}}{16 k_{2}^{2}} h^{2}$ there exists the unique solution of the finite difference scheme (2.1), (2.2), which converges to the solution of the problem (1.1), (1.2) as $h, \tau \rightarrow 0$ and for every $t \in \omega_{\tau}$ the following estimate

$$
\|z\|_{C\left(\omega_{h}\right)} \leq M \frac{h^{2}+\tau}{h^{3 / 2}}\|k\|_{C\left(\mathcal{D}_{u}\right)}\|u\|_{H^{2,1}\left(Q_{T}\right)} \leq \delta
$$

holds.

In the sequel, $M$ denotes a positive generic constant, independent of $h$ and $\tau$.

Proof We shall prove the assertion by means of mathematical induction. Evidently, for $t=0$ the estimate (2.6) holds. Suppose that for all $t^{\prime}=$ $0, \tau, \ldots, t$ the solution $y\left(x, t^{\prime}\right)$ of finite difference scheme $(2.1),(2.2)$ exists and estimate (2.6) holds. We will prove the same for $t^{\prime}=t+\tau$.

Firstly, we show that $\bar{u}+\theta z \in \mathcal{D}_{u}$. Obviously,

$$
\begin{aligned}
& \bar{u}-u_{1}=\frac{1}{h} \int_{x-h}^{x+h}\left(1-\frac{\left|x^{\prime}-x\right|}{h}\right) \times\left(u\left(x^{\prime}, t\right)-u_{1}\right) d x^{\prime} \geq 0, \\
& \bar{u}-u_{2}=\frac{1}{h} \int_{x-h}^{x+h}\left(1-\frac{\left|x^{\prime}-x\right|}{h}\right)\left(u\left(x^{\prime}, t\right)-u_{2}\right) d x^{\prime} \leq 0 .
\end{aligned}
$$

Consequently $\bar{u} \in \mathcal{M}_{u}$. Since $\|z(\cdot, t)\|_{C\left(\omega_{h}\right)} \leq \delta$, it follows that $\bar{u}+\theta z \in \mathcal{D}_{u}$, and the value $\kappa=k(\bar{u}+\theta z)$ is defined and $0<k_{1} \leq \kappa \leq k_{2}$. In such a manner the values $z$ (and $y$ ) for $t^{\prime}=t+\tau$, are defined. 
We estimate $\|z(\cdot, t+\tau)\|_{C\left(\omega_{h}\right)}$ by the energy method. Multiplying (2.5) in a scalar way with $2 \tau A^{-1} z$, we obtain

$$
\|\hat{z}\|_{A^{-1}}^{2}-\|z\|_{A^{-1}}^{2}-\tau^{2}\left\|z_{t}\right\|_{A^{-1}}^{2}+2 \tau(\kappa z, z)=2 \tau(\eta, z) .
$$

Substituting $z_{t}$ from equation (2.5), we obtain

$$
\|\hat{z}\|_{A^{-1}}^{2}-\|z\|_{A^{-1}}^{2}+2 \tau(\kappa z, z)=\tau^{2}\|\kappa z+\eta\|_{A}^{2}+2 \tau(\eta, z) .
$$

Using inequalities

$$
\begin{gathered}
\|\kappa z+\eta\|_{A}^{2} \leq 2\|\kappa z\|_{A}^{2}+2\|\eta\|_{A}^{2} \leq \frac{8 k_{2}^{2}}{h^{2}}\|z\|_{h}^{2}+\frac{8}{h^{2}}\|\eta\|_{h}^{2}, \\
2 \tau(\eta, z) \leq k_{1} \tau\|z\|_{h}^{2}+\tau \frac{1}{k_{1}}\|\eta\|_{h}^{2}, \quad 2 \tau(\kappa z, z) \geq 2 \tau k_{1}\|z\|_{h}^{2},
\end{gathered}
$$

we obtain

$$
\|\hat{z}\|_{A^{-1}}^{2}-\|z\|_{A^{-1}}^{2}+\tau\left(k_{1}-\frac{8 \tau k_{2}^{2}}{h^{2}}\right)\|z\|_{h}^{2} \leq \tau\left(\frac{1}{k_{1}}+\frac{8 \tau}{h^{2}}\right)\|\eta\|_{h}^{2} .
$$

Omitting positive the term with $\|z\|_{h}$ in the left side of (2.8), we obtain

$$
\|\hat{z}\|_{A^{-1}}^{2} \leq\|z\|_{A^{-1}}^{2}+\tau\left(\frac{1}{k_{1}}+\frac{8 \tau}{h^{2}}\right)\|\eta\|_{h}^{2} \leq\left(\frac{1}{k_{1}}+\frac{k_{1}}{2 k_{2}^{2}}\right) \sum_{t^{\prime}=0}^{t} \tau\left\|\eta\left(\cdot, t^{\prime}\right)\right\|_{h}^{2}
$$

Using representation

$$
\eta=\eta_{1}+\eta_{2}=\left(S_{t} \varphi(u)-S_{t} \varphi(\bar{u})\right)+\left(S_{t} \varphi(\bar{u})-\varphi(\bar{u})\right),
$$

and inequalities $\|v\|_{A^{-1}} \geq 0.5 h\|v\|_{h}$ and $\|v\|_{C\left(\omega_{h}\right)} \leq h^{-1 / 2}\|v\|_{h}$, from (2.9) we obtain

$$
\|\hat{z}\|_{C\left(\omega_{h}\right)}^{2} \leq \frac{4}{h^{3}}\left(\frac{1}{k_{1}}+\frac{k_{1}}{2 k_{2}^{2}}\right) 2 \tau \sum_{t^{\prime}=0}^{t}\left(\left\|\eta_{1}\left(\cdot, t^{\prime}\right)\right\|_{h}^{2}+\left\|\eta_{2}\left(\cdot, t^{\prime}\right)\right\|_{h}^{2}\right) .
$$

Further

$$
\begin{aligned}
\eta_{1}\left(x, t^{\prime}\right) & =\frac{1}{\tau} \int_{t^{\prime}}^{t^{\prime}+\tau}\left[\varphi\left(u\left(x, t^{\prime \prime}\right)\right)-\varphi\left(\bar{u}\left(x, t^{\prime \prime}\right)\right)\right] d t^{\prime \prime} \\
& =\frac{1}{\tau} \int_{t^{\prime}}^{t^{\prime}+\tau} \int_{\bar{u}\left(x, t^{\prime \prime}\right)}^{u\left(x, t^{\prime \prime}\right)} \varphi^{\prime}(w) d w d t^{\prime \prime}=\frac{1}{\tau} \int_{t^{\prime}}^{t^{\prime}+\tau} \int_{\bar{u}\left(x, t^{\prime \prime}\right)}^{u\left(x, t^{\prime \prime}\right)} k(w) d w d t^{\prime \prime} .
\end{aligned}
$$


From here it follows

$$
\begin{aligned}
& \left|\eta_{1}\left(x, t^{\prime}\right)\right| \leq \frac{1}{\tau}\|k\|_{C\left(\mathcal{D}_{u}\right)} \int_{t^{\prime}}^{t^{\prime}+\tau}\left|u\left(x, t^{\prime \prime}\right)-\bar{u}\left(x, t^{\prime \prime}\right)\right| d t^{\prime \prime} \\
& =\frac{1}{h \tau}\|k\|_{C\left(\mathcal{D}_{u}\right)} \int_{t^{\prime}}^{t^{\prime}+\tau}\left|\int_{x-h}^{x+h}\left(1-\frac{\left|x^{\prime}-x\right|}{h}\right)\left[u\left(x, t^{\prime \prime}\right)-u\left(x^{\prime}, t^{\prime \prime}\right)\right] d x^{\prime}\right| d t^{\prime \prime} \\
& =\frac{1}{h \tau}\|k\|_{C\left(\mathcal{D}_{u}\right)} \int_{t^{\prime}}^{t^{\prime}+\tau} \mid \int_{x-h}^{x+h}\left(1-\frac{\left|x^{\prime}-x\right|}{h}\right) \\
& \quad \times \int_{x^{\prime}}^{x} \int_{x}^{x^{\prime \prime}} \frac{\partial^{2} u\left(x^{\prime \prime \prime}, t^{\prime \prime}\right)}{\partial x^{2}} d x^{\prime \prime \prime} d x^{\prime \prime} d x^{\prime} \mid d t^{\prime \prime},
\end{aligned}
$$

and

$$
\left|\eta_{1}\left(x, t^{\prime}\right)\right| \leq \frac{M h^{2}}{\sqrt{h \tau}}\|k\|_{C\left(\mathcal{D}_{u}\right)}\left\|\frac{\partial^{2} u}{\partial x^{2}}\right\|_{L_{2}(e)},
$$

where $e=(x-h, x+h) \times\left(t^{\prime}, t^{\prime}+\tau\right)$. In an analogous manner we obtain

$$
\left|\eta_{2}\left(x, t^{\prime}\right)\right| \leq \frac{M \tau}{\sqrt{h \tau}}\|k\|_{C\left(\mathcal{D}_{u}\right)}\left\|\frac{\partial u}{\partial t}\right\|_{L_{2}(e)} .
$$

It follows from (2.10), (2.11) and (2.12) that

$$
\|z(\cdot, t+\tau)\|_{C\left(\omega_{h}\right)}=\|\hat{z}\|_{C\left(\omega_{h}\right)} \leq M \frac{h^{2}+\tau}{h^{3 / 2}}\|k\|_{C\left(\mathcal{D}_{u}\right)}\|u\|_{H^{2,1}\left(Q_{T}\right)} .
$$

Choosing sufficiently small $h$ and $\tau$ we finally obtain $\|z(\cdot, t+\tau)\|_{C\left(\omega_{h}\right)} \leq \delta$.

Theorem 2.2. Let the assumptions of theorem 2.1 are satisfied. Then the following estimate

$$
\|y-\bar{u}\|_{h \tau} \leq M\left(h^{2}+\tau\right)\|k\|_{C\left(\mathcal{D}_{u}\right)}\|u\|_{H^{2,1}\left(Q_{T}\right)}
$$

holds.

Proof From (2.8), summing over the mesh $\omega_{\tau}$ and using inequality $k_{1}-8 \tau k_{2}^{2} / h^{2} \geq \frac{k_{1}}{2}$, we obtain

$$
\|z(\cdot, T)\|_{A^{-1}}^{2}+\frac{k_{1}}{2} \tau \sum_{t=0}^{T-\tau}\|z\|_{h}^{2} \leq \tau\left(\frac{1}{k_{1}}+\frac{k_{1}}{2 k_{2}^{2}}\right) \sum_{t=0}^{T-\tau}\|\eta\|_{h}^{2} .
$$


Applying to (2.14) estimates (2.11) and (2.12) and omitting the term $\|z(\cdot, T)\|_{A^{-1}}^{2}$ we obtain (2.13).

Since the solution $u$ is a continuous function it is interesting to estimate the difference $y-u$.

Theorem 2.3. Let the assumptions of theorem 2.1 are satisfied. Then the following estimate holds

$$
\|y-u\|_{h \tau} \leq M\left(h^{2}+\tau\right)\left(\|k\|_{C\left(\mathcal{D}_{u}\right)}+1\right)\|u\|_{H^{2,1}\left(Q_{T}\right)} .
$$

\section{IMPLICIT FINITE DIFFERENCE SCHEME}

We assume, that there exists a unique solution $u(x, t)$ of the problem (1.1), (1.2) in $H^{3,3 / 2}\left(Q_{T}\right)$, and $u_{0} \in H^{2}(0,1), k \in C\left(\mathcal{D}_{u}\right), 0<k_{1} \leq k(v) \leq k_{2}$ for $v \in \mathcal{D}_{u}$.

We approximate the problem (1.5), (1.2) with implicit finite difference scheme

$$
\begin{gathered}
\left.y_{t}=\left(a(y) \hat{y}_{\bar{x}}\right)\right)_{x},(x, t) \in \omega_{h \tau}, \\
y(0, t)=y(1, t)=0, t \in \bar{\omega}_{\tau}, \quad y(x, 0)=S_{x} u_{0}(x), x \in \omega_{h},
\end{gathered}
$$

where $a(y(x))=k((0.5(y(x)+y(x-h)))$.

Let us consider the convergence of finite difference scheme (3.1), (3.2). Having the solution $u(x, t)$ of the problem (1.5), (1.2) oddly extended outside of $Q_{T}$, suppose that $\bar{u}=S_{x}^{2} u$. The following identity takes place

$$
\bar{u}_{t}=S_{t}\left(k(u(x-0.5 h, t)) \frac{\partial u}{\partial x}(x-0.5 h, t)\right)_{x} .
$$

Using the identity (3.3), we can write a problem for $z=y-\bar{u}$ in the form

$$
\begin{gathered}
z_{t}=\left(a(y) \hat{z}_{\bar{x}}\right)_{x}+\left((a(y)-a(\bar{u})) \hat{\bar{u}}_{\bar{x}}\right)_{x}+\eta_{x}(x, t),(x, t) \in \omega_{h \tau} \\
z(0, t)=z(1, t)=0, t \in \bar{\omega}_{\tau}, \quad z(x, 0)=0, x \in \omega_{h}
\end{gathered}
$$

where

$$
\eta(x, t)=\left(a(\bar{u}) \hat{\bar{u}}_{\bar{x}}\right)(x, t)-S_{t} k(u(x-0.5 h, t)) \frac{\partial u}{\partial x}(x-0.5 h, t) .
$$

For our convenience, let us represent $\eta(x, t)$ as below

$$
\eta(x, t)=\frac{1}{\tau} \int_{t}^{t+\tau}\left\{\left[a(\bar{u}(x, t))-k\left(u\left(x-0.5 h, t^{\prime}\right)\right)\right] \bar{u}_{\bar{x}}(x, t+\tau)+k\left(u\left(x-0.5 h, t^{\prime}\right)\right)\right.
$$




$$
\begin{gathered}
\left.\times\left[\bar{u}_{\bar{x}}(x, t+\tau)-\frac{\partial u}{\partial x}\left(x-0.5 h, t^{\prime}\right)\right]\right\} d t^{\prime} \\
=\frac{1}{\tau} \int_{t}^{t+\tau}\left\{\eta_{1}\left(x, t, t^{\prime}\right) \bar{u}_{\bar{x}}(x, t+\tau)+k\left(u\left(x-0.5 h, t^{\prime}\right)\right) \eta_{2}\left(x, t, t^{\prime}\right)\right\} d t^{\prime} .
\end{gathered}
$$

First, we shall estimate $\eta_{2}\left(x, t, t^{\prime}\right)$. For this purpose, we shall take an advantage of the obvious identity

$$
\bar{u}_{\bar{x}}(x, t+\tau)=\frac{1}{h^{2}} \int_{x-h x^{\prime}-0.5 h}^{x} \int_{x^{\prime}+0.5 h} \frac{\partial u}{\partial x}\left(x^{\prime \prime}, t+\tau\right) d x^{\prime \prime} d x^{\prime}
$$

Using (3.6), we obtain

$$
\begin{aligned}
\eta_{2}\left(x, t, t^{\prime}\right) & =\bar{u}_{\bar{x}}(x, t+\tau)-\frac{\partial u}{\partial x}\left(x-0.5 h, t^{\prime}\right) \\
& =\frac{1}{h^{2}} \int_{x-h}^{x} \int_{x^{\prime}-0.5 h}^{x^{\prime}+0.5 h}\left(\frac{\partial u}{\partial x}\left(x^{\prime \prime}, t+\tau\right)-\frac{\partial u}{\partial x}\left(x-0.5 h, t^{\prime}\right)\right) d x^{\prime \prime} d x^{\prime} \\
& =\frac{1}{h^{2}} \int_{x-h}^{x} \int_{x^{\prime}-0.5 h}^{x^{\prime}+0.5 h} \int_{t^{\prime}}^{t+\tau} \frac{\partial^{2} u}{\partial x \partial t}\left(x^{\prime \prime}, t^{\prime \prime}\right) d t^{\prime \prime} d x^{\prime \prime} d x^{\prime} \text { nonumber } \\
& +\frac{1}{h^{2}} \int_{x-h x^{\prime}-0.5 h}^{x} \int_{x^{\prime}+0.5 h}^{x^{\prime \prime}}\left(x^{\prime \prime}-x^{\prime \prime \prime}\right) \frac{\partial^{2} u}{\partial x^{2}}\left(x^{\prime \prime \prime}, t^{\prime}\right) d x^{\prime \prime \prime} d x^{\prime \prime} d x^{\prime} .(3.8)
\end{aligned}
$$

Integrating $\left|\eta_{2}\left(x, t, t^{\prime}\right)\right|$ over $t^{\prime} \in(t, t+\tau)$, applying the Cauchy-SchwartzBunyakovskii inequality and taking into account the estimate (3.8), we obtain

$$
\frac{1}{\tau} \int_{t}^{t+\tau}\left|\eta_{2}\left(x, t+\tau, t^{\prime}\right)\right| d t^{\prime} \leq \frac{\sqrt{\tau}}{\sqrt{h}}\left\|\frac{\partial^{2} u}{\partial t \partial x}\right\|_{L_{2}(e)}+\frac{h \sqrt{h}}{\sqrt{\tau}}\left\|\frac{\partial^{3} u}{\partial x^{3}}\right\|_{L_{2}(e)}
$$

where $e=(x-1.5 h, x+0.5 h) \times(t, t+\tau)$.

To estimate $\eta_{1}\left(x, t, t^{\prime}\right)$, we use the relation

$$
u\left(x-0.5 h, t^{\prime}\right)=\frac{u\left(x-h, t^{\prime}\right)+u\left(x, t^{\prime}\right)}{2}-\frac{1}{2} \int_{x-0.5 h}^{x} \int_{x^{\prime}-0.5 h}^{x^{\prime}} \frac{\partial^{2} u}{\partial x^{2}}\left(x^{\prime \prime}, t^{\prime}\right) d x^{\prime \prime} d x^{\prime} .
$$


Then the following expressions are valid

$$
\begin{aligned}
\eta_{1}\left(x, t, t^{\prime}\right) \leq & a(\bar{u}(x, t))-k\left(u\left(x-0.5 h, t^{\prime}\right)\right) \\
\leq & L\left|0.5(\bar{u}(x-h, t)+\bar{u}(x, t))-u\left(x-0.5 h, t^{\prime}\right)\right| \\
\leq & \frac{L}{2} \mid \bar{u}(x-h, t)-u\left(x-h, t^{\prime}\right)+\bar{u}(x, t)-u\left(x, t^{\prime}\right) \\
& \quad+\int_{x-0.5 h}^{x} \int_{x^{\prime}-0.5 h}^{x^{\prime}} \frac{\partial^{2} u}{\partial x^{2}}\left(x^{\prime \prime}, t^{\prime}\right) d x^{\prime \prime} d x^{\prime} \mid \\
\leq & \frac{L}{2}\left(\left|\frac{1}{h} \int_{x-0.5 h}^{x+0.5 h} \int_{t^{\prime}}^{t} \frac{\partial u}{\partial t}\left(x^{\prime}, t^{\prime}\right) d t^{\prime} d x^{\prime}\right|\right. \\
& +\mid \frac{1}{h} \int_{x-0.5 h}^{x+0.5 h} \int_{x}^{x^{\prime}}\left(x^{\prime \prime}-x^{\prime}\right)\left(\frac{\partial^{2} u}{\partial x^{2}}\left(x^{\prime \prime}, t^{\prime}\right)+\frac{\partial^{2} u}{\partial x^{2}}\left(x^{\prime \prime}-h, t^{\prime}\right) d x^{\prime \prime} d x^{\prime} \mid\right. \\
& \left.+\left|\int_{x-0.5 h}^{x} \int_{x^{\prime}-0.5 h}^{x^{\prime}} \frac{\partial^{2} u}{\partial x^{2}}\left(x^{\prime \prime}, t^{\prime}\right) d x^{\prime \prime} d x^{\prime}\right|\right) .
\end{aligned}
$$

Integrating $\left|\eta_{1}\left(x, t, t^{\prime}\right)\right|$ over $t^{\prime} \in(t, t+\tau)$ and taking into account the inequality (3.10), we obtain

$$
\frac{1}{\tau} \int_{t}^{t+\tau}\left|\eta_{1}\left(x, t, t^{\prime}\right)\right| d t^{\prime} \leq L\left(\frac{\sqrt{\tau}}{\sqrt{h}}\left\|\frac{\partial u}{\partial t}\right\|_{L_{2}(e)}+\frac{h^{3 / 2}}{\sqrt{\tau}}\left\|\frac{\partial^{2} u}{\partial x^{2}}\right\|_{L_{2}(e)}\right) .
$$

It is not easy to show ([2], vol.2, pp.10-11) that

$$
\left|\bar{u}_{\bar{x}}(x, t+\tau)\right| \leq \max _{x \in[0,1]}\left|\bar{u}_{\bar{x}}(x, t+\tau)\right| \leq M\|u(\cdot, t+\tau)\|_{W_{2}^{3,3 / 2}\left(Q_{T}\right)} .
$$

Combining the estimates (3.8), (3.10), (3.11), we obtain a priori estimate for $\eta(x, t)$

$$
\begin{aligned}
|\eta(x, t)| \leq\left|\bar{u}_{\bar{x}}(x, t+\tau)\right| \frac{1}{\tau} \int_{t}^{t+\tau}\left|\eta_{1}\left(x, t, t^{\prime}\right)\right| d t^{\prime} \\
+\|k(u)\|_{C\left(\mathcal{D}_{u}\right)} \frac{1}{\tau} \int_{t}^{t+\tau}\left|\eta_{2}\left(x, t+\tau, t^{\prime}\right)\right| d t^{\prime} .
\end{aligned}
$$

Then summing $\eta(x, t)$ over the grid points $\left\{\bar{\omega}_{\tau} \backslash\{t=T\}\right\} \times\left\{\bar{\omega}_{h} \backslash\{x=1\}\right\}$, we 
obtain

$$
\begin{aligned}
\left.\left.\left(\sum_{t=0}^{T-\tau} \tau \| \eta\right]\right|^{2}\right)^{1 / 2} \leq & M\left(\tau\left\|\frac{\partial u}{\partial t}\right\|_{L_{2}\left(Q_{T}\right)}+h^{2}\left\|\frac{\partial^{3} u}{\partial x^{3}}\right\|_{L_{2}\left(Q_{T}\right)}\right) \\
& \times\left(\|u(\cdot, t+\tau)\|_{W_{2}^{3,3 / 2}\left(Q_{T}\right)}+1\right) .
\end{aligned}
$$

Theorem 3.1. Suppose there exists the unique solution of the problem (1.1), (1.2) in $H^{3,3 / 2}\left(Q_{T}\right), k \in C\left(\mathcal{D}_{u}\right), 0<k_{1} \leq k(v) \leq k_{2}$ for $v \in \mathcal{D}_{u}$. Then, for sufficiently small $h<h_{0}, \tau<\tau_{0}$ there exists the unique solution of the finite difference scheme (3.1), (3.2), which converges to the solution of the problem (1.1), (1.2) as $h, \tau \rightarrow 0$ and for any $t \in \omega_{\tau}$ the following estimates

$$
\begin{gathered}
\left.\|z\|_{*} \leq M\left(h^{2}+\tau\right)\|u\|_{W_{2}^{3,3 / 2}\left(Q_{T}\right)}, \quad\|z\|_{*}^{2}=\|z\|^{2}+\tau k_{1} \| z_{\bar{x}}\right]\left.\right|^{2}, \\
\|z\|_{C\left(\omega_{h}\right)} \leq M(h+\sqrt{\tau})\|u\|_{W_{2}^{3,3 / 2}\left(Q_{T}\right)} \leq \delta
\end{gathered}
$$

hold.

Proof We shall prove the assertion by means of mathematical induction. Obviously, that for $t=0$ the estimates (3.15), (3.14) hold. Suppose that for all $t^{\prime}=0, \tau, \ldots, t$ the solution $y\left(x, t^{\prime}\right)$ of the finite difference scheme (3.1), (3.2) exists and the estimate (3.15) holds. To prove the same for $t^{\prime}=t+\tau$, we shall use the energy method. Considering an inner product of (3.4) and $2 \tau \hat{z}$, we obtain the energy identity

$$
\|\hat{z}\|^{2}-\|z\|^{2}+\tau\left\|z_{t}\right\|^{2}+2 \tau\left(a(y) \hat{z}_{\bar{x}}, \hat{z}_{\bar{x}}\right]+2 \tau\left((a(y)-a(\bar{u})) \hat{\bar{u}}_{\bar{x}}, \hat{z}_{\bar{x}}\right]=-2 \tau\left(\eta, \hat{z}_{\bar{x}}\right) .
$$

Then

$$
\begin{gathered}
\left.2 \tau\left(a(y) \hat{z}_{\bar{x}}, \hat{z}_{\bar{x}}\right) \geq 2 \tau k_{1} \| \hat{z}_{\bar{x}}\right]\left.\right|^{2} \\
\left.2 \tau\left((a(y)-a(\bar{u})) \hat{\bar{u}}_{\bar{x}}, \hat{z}_{\bar{x}}\right] \leq \frac{\tau k_{1}}{2} \| \hat{z}_{\bar{x}}\right]\left.\right|^{2}+\frac{\tau}{2 k_{1}} M^{2} L^{2}\|u\|_{W_{2}^{3,3 / 2}\left(Q_{T}\right)}^{2}\|z\|^{2} \\
\left.\left.2 \tau\left(\eta, \hat{z}_{\bar{x}}\right) \leq \frac{\tau k_{1}}{2} \| \hat{z}_{\bar{x}}\right]\left.\right|^{2}+\frac{\tau}{2 k_{1}} \| \eta\right]\left.\right|^{2} .
\end{gathered}
$$

Summing over these estimates, we get the energy inequality

$$
\begin{aligned}
\|\hat{z}\|_{*}^{2} & \left.\leq(1+\tau M)\|z\|_{*}^{2}+\frac{\tau}{2 k_{1}} \| \eta\right]\left.\right|^{2} \\
& \left.\left.\leq M \sum_{t^{\prime}=0}^{t} \tau \| \eta\left(t^{\prime}\right)\right]\left.\right|^{2} \leq M \sum_{t^{\prime}=0}^{T-\tau} \tau \| \eta\left(t^{\prime}\right)\right]\left.\right|^{2} .
\end{aligned}
$$

Substituting the estimate (3.13) into (3.16), we obtain (3.14). The inequality (3.15) follows from Theorem 1 ([11]). 


\title{
REFERENCES
}

[1] I. P. Gavrilyuk, R. D. Lazarov, V. L. Makarov and S. P. Pirnazarov. Estimates of the convergence rate of difference solutions to solutions of the second boundary value problem for fourth order equation at minimal requirements to smoothness. Doklady AN USSR, Ser. A (2), 1983, 6 - 9.(in Russian)

[2] J. L. Lions, E. Magenes. Problèmes aux limites non homogènes et applications. Paris: Dunod, 1968.

[3] V. L. Makarov and N. V. Slushaenko. Consistent estimates of the rate of convergence of a mesh method for quasilinear elliptic equations with large Lipschitz constants. Differents. uravneniya, 19 (7), 1983, 1219 - 1226.(in Russian)

[4] P. P. Matus, M. N. Moskal'kov and V. S. Shchehlik. Consistent estimates for rate of convergence of the grid method for a second-order nonlinear equation with generalized solutions. Differents. uravneniya, 31 (7), 1995, 1249 - 1256.(in Russian)

[5] A. A. Samarskii. Theory of difference schemes. Moscow: Nauka, 1983. (in Russian)

[6] A. A. Samarskii. Investigation of the accuracy of difference schemes for problems with generalized solutions. Current problems in mathematical physics and numerical mathematics, Nauka, Moscow, 1984, 174 - 183.(in Russian)

[7] A. A. Samarskii, R. D. Lazarov, and V. L. Makarov. Finite difference schemes for differential equations with generalized solutions. Vysshaya shkola, Moscow, 1987. (in Russian)

[8] A. A. Samarskii, P. P. Matus, B. S. Jovanovich, and V. S. Shchehlik. Finite difference schemes on time-adaptive meshes for parabolic equations with generalized solutions. Differentsial'nye uravneniya, 33 (7), 1997, 975 - 984.(in Russian)

[9] A. A. Samarskii, P. N. Vabishchevich, and P. P. Matus. Finite difference schemes with operator factors. Minsk, 1998. (in Russian)

[10] V. S. Shchehlik. Analysis of a difference scheme approximating the third boundary value problem for a second-order nonlinear differential equation. Zh. vychisl. mat. mat. fiz, 37 (8), 1995, 951 - 957.(in Russian)

[11] P. P. Matus. Vesti ANB. (4), 1993, 15 - 21. (in Russian)

\section{BAIGTINIŲ SKIRTUMŲ SCHEMŲ, APROKSIMUOJANČIŲ SILPNUOSIUS NETIESINÉS ŠILUMOS LYGTIES SPRENDINIUS, TIKSLUMO IVERCIAI}

\author{
B.S. JOVANOVIČ, P.P. MATUS, V.S. SHCHEHLIK
}

Nagrinëjami vienmatès netiesinès šilumos laidumo lygties skaitiniai sprendimo metodai, kai lygtis turi tik silpnąji sprendinic. Lygties koeficientai yra stipriai netiesiniai. Ištirtos išreikštinè ir neišreikštinè baigtinių skirtumuc schemos. Aproksimuojant funkcijas panaudoti Steklovo vidurkinimo operatoriai. Gautieji paklaidu iverčiai yra suderinti su diferencialinio uždavinio sprendinio glodumu. 